\title{
CARTOGRAFANDO A LINGUAGEM NO ENSINO MÉDIO
}

\author{
CARTOGRAPHING LANGUAGE IN HIGH SCHOOL
}

Wesley Magalhães Viana ${ }^{1}$

\begin{abstract}
Resumo: Este trabalho tem como objetivo estudar a linguagem em uma perspectiva interacionista, a partir de sua relação com o ensino de língua portuguesa no Ensino Médio. Para isso, linguagem e ensino são conectados à filosofia de Gilles Deleuze e Félix Guattari (1980), a fim de analisar a subjetividade construída na instituição escola. Em seguida, movimentos de fuga são sinalizados a partir de linhas éticas, estéticas e políticas presentes no componente de língua portuguesa do Ensino Médio, na Base Nacional Comum Curricular (BRASIL, 2018), guia normativo para a educação básica no Brasil. Com isso, acreditamos ser possível pensar um ensino de língua portuguesa que não reproduza o poder do Estado.
\end{abstract}

Palavras-chave: Linguagem; ensino; poder.

\begin{abstract}
This work aims to study language in an interactionist perspective, from its relationship with the teaching of Portuguese in high school. For this, language and teaching are connected to the philosophy of Gilles Deleuze and Félix Guattari (1980), in order to analyze the subjectivity built in the school institution. Then, escape movements are signaled based on ethical, aesthetic and political lines present in the Portuguese language component of Secondary Education, at the National Common Curricular Base (BRASIL, 2018), a normative guide for basic education in Brazil. With this, we believe it is possible to think of a Portuguese language teaching that does not reproduce the power of the State.
\end{abstract}

Keywords: Language; teaching; power.

\section{Introdução}

Em O que é a filosofia? (1991), Gilles Deleuze e Félix Guattari propõem uma cartografia não hierárquica do pensamento, dividida em três caóides de conhecimento: Filosofia, Ciência e Arte. Para eles, essas três dimensões criam modos de pensar. A Filosofia é responsável por criar conceitos; a Ciência, por sua vez, cria funções; e a Arte cria perceptos e afectos. Nesse sentido, há uma distinção dos modos de criação de pensamento que caracterizam os diversos saberes.

Existem vários modos de produzir algo novo. Por estarem sempre se relacionando, não há uma separação rígida entre as três caóides. Quando a arte encontra a filosofia, surge uma zona de indiscernibilidade entre sensação e conceito. Quando a filosofia encontra a ciência, borram-se as fronteiras entre conceito e função. Desse modo, para criar pensamentos, é possível habitar esses espaços rizomáticos entre.

Este artigo divide-se em dois tópicos. Nossos movimentos começam pela relação entre linguagem e ensino, apresentando problemas em um tipo de ensino, cujo objetivo é reconhecer e receber linguagem de uma realidade dominante, e em seguida propomos relações entre rizoma ${ }^{2}$ e educação, com vistas à BNCC, cujo caráter normativo à educação básica também sinaliza

\footnotetext{
${ }^{1}$ Universidade Estadual do Ceará (UECE), CE, Brasil.

${ }^{2}$ Rizoma é um conceito de Deleuze e Guattari e pode ser encontrado no livro Mil Platôs (1980). Originalmente, a obra foi publicada em um único volume, mas no Brasil o livro foi dividido em cinco volumes. O capítulo Introdução: Rizoma é o primeiro platô e compõe o primeiro volume da edição brasileira. Para Deleuze e Guattari, um rizoma produz alianças entre coisas heterogêneas, mas não alianças por subordinação. Dependendo daquilo a que se conecta, um rizoma se decompõe, se acopla com outras coisas e, assim, cria algo diferente.
} 
movimentos rizomáticos, por meio de linhas éticas, estéticas e políticas, quando apresenta a língua portuguesa no Ensino Médio. Propor uma intervenção nesse ensino normativo também lança o nosso olhar a processos de criação numa linguagem que opera por repetição.

\section{Linguagem e ensino}

A instituição escola é um dos órgãos responsáveis por criar pensamentos, entre eles, o linguístico. No entanto, dentre todos os estudos sobre a linguagem, um dos direcionamentos que mais interessa ao Estado, na educação básica, é o estudo de uma gramática em situações reais de uso. Mas não interessa ao Estado, por exemplo, ensinar as condições de existência da linguagem: Como a linguagem é criada? A serviço de que/quem está a linguagem em uso?

No Ensino Médio, é comum ensinarmos aos alunos conhecimentos predeterminados por relações de poder. Porém, não é comum ensinar-lhes criticamente sua situação desfavorecida em sociedade, para agirem em favor de sua própria libertação. Pelo contrário: ensinamos a eles linguagem para se encaixarem nos modelos preexistentes da sociedade e, nesse processo, avaliamos sua capacidade de recognição. Assim, palavras de ordem são reconhecidas, obedecidas, armazenadas e repetidas em enunciados permitidos pelo Estado.

No livro Mil platôs (1980), no platô 4 Postulados da lingüística, Deleuze e Guattari apontam a linguagem a serviço de um sistema de comandos, dados a partir de palavras de ordem. Nesse sentido, a subjetividade construída na instituição escola opera pelo reconhecimento normativo de um modo de pensar, de enunciar e de agir, e o não cumprimento dessa subjetividade implica reprovações.

A unidade elementar da linguagem - o enunciado - é a palavra de ordem. Mais do que o senso comum, faculdade que centralizaria as informações, é preciso definir uma faculdade abominável que consiste em emitir, receber e transmitir as palavras de ordem. [...] Isso pode ser percebido nos informes da polícia ou do governo, que pouco se preocupam com a verossimilhança ou com a veracidade, mas que definem muito bem o que deve ser observado e guardado. (DELEUZE; GUATTARI, 2019, p. 12, grifos nossos)

Os enunciados produzidos nas aulas de língua portuguesa também transmitem palavras de ordem, isto é, aquilo que deve ser observado, guardado e usado durante as avaliações internas e externas à instituição. Não queremos demonizar esse processo, inclusive, sabemos que é preciso haver homogeneidade nos conteúdos para que avaliações em larga escala possam ser executadas, para que pesquisas científicas possam ser feitas.

Em Três questões sobre Seis vezes dois (Godard) (1976), no livro Conversações ${ }^{3}$, Deleuze (2017, p. 57-58) já mencionava que "a linguagem é um sistema de comando, não um meio de informação". Para ele, a linguagem expressa suas palavras de ordem quando, por exemplo, a professora ensina ortografia na escola, ou quando a televisão sinaliza como devemos sentir, "Agora vamos nos divertir..., e logo mais as notícias" (DELEUZE, 2017, p. 58). Nessa lógica, ou o sujeito participa dos enunciados reproduzidos pela realidade dominante, ou se ausenta dela.

A língua portuguesa no Ensino Médio não contempla o fora da linguagem, isto é, suas zonas de indiscernibilidade. Pelo contrário: ensinamos aos alunos receber linguagem. Embora a

\footnotetext{
3 "Este volume, que reúne entrevistas concedidas ao longo de vinte anos, além de cartas e ensaios sobre política, literatura e televisão, forma um belo guia introdutório ao pensamento de Deleuze." (PELBART, Peter Pál, 2017, orelha do livro). Reunidas entre 1972-1990, as Conversações (1992) foram publicadas no Brasil pela Editora 34. O livro é organizado em cinco capítulos: 1) De o Anti-Édipo a Mil Platôs; 2) Cinema; 3) Michel Foucalt; 4) Filosofia; 5) Política. Atualmente, está em sua 3 $3^{\mathrm{a}}$ edição (2013), com reimpressão em 2017.
} 
(re)cognição seja uma habilidade necessária à educação básica, ao ensiná-la — e somente ela instruímos os nossos alunos a reconhecerem coisas numa realidade já construída e interpretada, a apontarem semelhanças nessa realidade, a repetirem enunciados em interações casmurras ${ }^{4}$. Ensinamos aos nossos alunos reconhecer e receber linguagem em uma realidade dominante, mas não os ensinamos a criar linguagem nessa ou contra essa realidade. Que modos de existência isso implica?

\section{Linhas rizomáticas na Base Nacional Comum Curricular}

A Base Nacional Comum Curricular (BNCC) propõe ao professor, durante o Ensino Médio, a oportunidade de aprofundar o aprendizado já construído nos anos anteriores, possibilitando uma participação mais plena das juventudes em diferentes práticas de linguagens. "Tais oportunidades também devem ser orientadas para a criação e o encontro com o inusitado, com vistas a ampliar os horizontes éticos e estéticos dos estudantes" (BRASIL, 2018, p. 486).

Sabendo que as novas tecnologias digitais apresentam textos e discursos organizados de maneira multimodal e multissemiótica, é urgente pensar um ensino que não se limite à aquisição de um código visual, embora seja importante aprendê-lo. No Ensino Médio, o professor precisa de intensidades outras, pois segundo a BNCC (BRASIL, 2018, p. 499), as "habilidades requeridas por processos de recuperação de informação (identificação, reconhecimento, organização) e por processos de compreensão (comparação, distinção, estabelecimento de relações e inferência) já foram desenvolvidas no Ensino Fundamental”.

A língua portuguesa, no Ensino Médio, é atravessada por linhas éticas, estéticas e políticas, marcadas linguisticamente na BNCC. No entanto, o documento não desenvolve a aplicação desses conceitos, nem sinaliza os agenciamentos aos quais pertencem. $O$ texto introdutório propõe ao professor valer-se dessas ferramentas para "aprofundar a análise sobre as práticas de linguagem e seus funcionamentos [...] e alargar as referências éticas, estéticas e políticas que cercam a produção e recepção de discursos” (BRASIL, 2018, p. 498).

Nesse sentido, a BNCC não apresenta currículo, nem práticas pedagógicas, pois trata-se de um guia para a construção dos currículos de cada instituição. Para o Ensino Médio, o documento direciona as linhas do ensino a cinco campos de atuação social: 1) campo da vida pessoal; 2) campo da vida pública; 3) campo jornalístico-midiático; 4) campo artístico-literário; 5) campo das práticas de estudo e pesquisa.

De modo geral, os campos de atuação social apresentam várias interseções compromissadas com o protagonismo estudantil, valorizando a diversidade cultural, a análise linguística e a semiótica, os gêneros digitais e as tecnologias, a leitura crítica de textos. Esses campos operam como eixos organizadores das Competências Específicas de Linguagens e suas Tecnologias para o Ensino Médio ${ }^{5}$ e consideram tanto a cultura digital quanto os multiletramentos e os novos letramentos.

As práticas de leitura e produção de textos que são construídos a partir de diferentes linguagens ou semioses são consideradas práticas de multiletramentos, na medida em que exigem letramentos em diversas linguagens, como as visuais, as sonoras, as verbais e as corporais. Já os novos letramentos remetem a um conjunto de práticas específicas da mídia digital

\footnotetext{
${ }^{4}$ Segundo o dicionário Houaiss (2009), casmurro adjetiva um indivíduo fechado em si mesmo, ensimesmado. Em nosso caso, as interações casmurras referem-se a um ensino-aprendizagem tradicional, focado em repetir regras de funcionamento da linguagem em seus modelos seriados, sem considerar as operações ideológicas, bem como as relações de poder nelas implicadas. Quando amparados em interações casmurras, professores e estudantes reproduzem enunciados que legitimam o poder rígido do Estado, desse modo, embrutecendo a vida.

${ }^{5}$ Cf. BRASIL, 2018, p. 490.
} 
que operam a partir de uma nova mentalidade, regida por uma ética diferente (BRASIL, 2018, p. 487, grifos nossos).

Embora a BNCC não assuma currículo ou estratégias de ensino, o documento legitima conexões com teorias contemporâneas de letramentos, desse modo, assumindo a linguagem como prática social. Assim sendo, a antiga concepção estruturalista da linguagem — como um sistema estático de regras e formas - abre espaço para um processo contínuo de transformação da realidade, a partir de novas interações.

Os letramentos são mote de pesquisas há algumas décadas, e suas variadas perspectivas enriquecem as contribuições para o ensino. As discussões desse assunto acompanham os estudos sobre a escrita, de modo geral, desde a segunda metade do século XX. Porém, com o rápido avanço das tecnologias, foi necessário pensar novos parâmetros para a formação básica. Desse modo, ao professor de língua portuguesa cabe também a tarefa de letrar estudantes para que eles possam relacionar semioses, usando as novas tecnologias. Nessa perspectiva, Street (2014, p. 13 apud PINHEIRO, 2018, p. 24) reconhece que "as práticas de leitura e escrita estão sempre inseridas não só em significados culturais, mas em alegações ideológicas sobre o que conta como ‘letramento' e as relações de poder a ele associadas", ampliando assim esses estudos para o campo do Discurso.

Nesse campo extralinguístico, acreditamos na cartografia de fluxos de intensidade, como bússola a guiar o professor pelas multiplicidades. Desse modo, quando se movimenta, o professor se deixa afetar por um plano de linhas e de forças coletivas, que vêm de todos os lados e vão para todos os lados. Seu trabalho é identificar quais linhas favorecem a vida e a diferença, dando-lhes potência.

\section{Considerações finais}

A linguagem hoje é organizada de maneira multimodal e multissemiótica e, desse modo, assume uma perspectiva interacionista com outras linguagens e com outras áreas de conhecimento. Embora ainda seja comum análises linguísticas se concentrarem na linguagem verbal, documentos oficiais e pesquisas científicas legitimam novos caminhos para a o ensino de língua portuguesa quando discutem outras semioses além da verbal e quando ampliam seus paradigmas para o campo extralinguístico.

Apesar de ser um documento normativo, a BNCC também possui movimentos transversais para o ensino de língua portuguesa, no Ensino Médio, a partir de linhas éticas, estéticas e políticas aliadas às linguagens. Com esses movimentos, é possível fazer travessias entre as linguagens, mas para isso é necessária uma força transversal. De modo algum desmerecemos as teorias com base em uma estrutura, inclusive, entendemos a gramática como um dos objetos de estudo no Ensino Médio, mas esperamos do leitor sensibilidade a essa descentralização, pois não queremos apenas repetir, mas também criar.

\section{Referências}

BRASIL. Base Nacional Comum Curricular. Brasília: MEC, 2018. Disponível em: http://basenacionalcomum.mec.gov.br/images/BNCC_20dez_site.pdf. Acesso em: 15 jun. 2020.

DELEUZE, Gilles. Conversações. Trad. Peter Pál Pelbart. São Paulo: Editora 34, 2017.

DELEUZE, Gilles; GUATTARI, Félix. O que é a Filosofia? Trad. Bento Prado Jr. e Alberto Alonso Muños. São Paulo: Editora 34, 2016. 
DELEUZE, Gilles; GUATTARI, Félix. Mil platôs: capitalismo e esquizofrenia. v. 1. Trad. Aurélio Guerra Neto et al. Rio de Janeiro: Editora 34, 2019.

DELEUZE, Gilles; GUATTARI, Félix. Mil platôs: capitalismo e esquizofrenia. v. 2. Trad. Aurélio Guerra Neto et al. Rio de Janeiro: Editora 34, 2019.

HOUAISS, Antônio (dir.). Dicionário Eletrônico Houaiss da Língua Portuguesa 3.0. Rio de Janeiro: Objetiva, 2009.

PINHEIRO, Izabelle Girão. Letramento Multimodal Crítico com fotografias em aulas de língua portuguesa. Dissertação (Mestrado Profissional em Letras) - Centro de Humanidades, Universidade Estadual do Ceará, Fortaleza, 2018.

\section{Sobre o autor}

Wesley Magalhães Viana é graduado em Letras, pela Universidade Federal do Ceará, Especialista em Ensino de Língua Portuguesa, pela Universidade Estadual do Ceará, e Mestrando em Letras, pela Universidade Estadual do Ceará. Atualmente, investiga articulações entre o ensino de língua portuguesa e o uso de fotografias, a partir da filosofia de Gilles Deleuze. E-mail: wmvhlv@gmail.com. 